\title{
Scuba Diving Experience and Sustainability: An Assessment of Online Travel Reviews
}

\author{
Perunjodi Naidoo*, Prabha Ramseook-Munhurrun** and Jing Li***
}

\begin{abstract}
Scuba diving is a popular activity in small island destinations which is on the rise. However, it is particularly important to preserve the physical environment for small island developing states due to their unique biodiversity and fragile ecosystems. Scuba diving tourism in island destinations is provided mainly by dive operators who are responsible to deliver the scuba diving experience to tourists. However, despite the importance of sustainability for the tourism industry, it is unclear to which extent the marine environment or green issues are important for consumers. Studies are increasingly suggesting that sustainability is an important feature considered by consumers. However, information is sparse regarding the extent to which sustainability is a key component for customers when evaluating the scuba diving experience. In this study, 3109 text reviews from the Tripadvisor website across all 57 listed diving operators in Mauritius were selected for data analysis. The present study uses Leximancer, a text analysis software that conducts unsupervised analysis of natural language texts provided in an electronic format.
\end{abstract}

Keywords: scuba diving, tourism experience, sustainability, leximancer, Mauritius

\section{Introduction}

Dive tourism is one of the fastest growing components of the tourism sector (Merchant, 2011) and has become a multi-billion dollar industry (Tapsuwan \& AsafuAdjaye, 2008) and it is estimated that in the United States alone there are between 1.62.9 million divers (Professional Association of Diving Instructors, 2005). Improved access to diving sites, affordable equipment, advances in technology and training have contributed to a burgeoning industry (Dinmock \& Musa, 2015).

\footnotetext{
* University of Technology Mauritius, La Tour Koenig Pointe aux Sables, Mauritius. Email: pnaidoo@umail.utm.ac.mu

** University of Technology Mauritius, La Tour Koenig Pointe aux Sables, Mauritius.

*** James Cook University, Townsville, Queensland, Australia
} 
Coral reefs are popular tourism sites (Kirkbride-Smith et al., 2013; Giglio et al., 2015) and are prised amongst divers because of the wide variety of marine life they support and their visual attractiveness (Hawkins \& Roberts, 1992). However, scuba diving also generates pressure on the local environment and its ecosystems (Dinmock \& Musa, 2015) and, as a result, the marine environment is a conspicuous example of "beautiful and fascinating natural environments vulnerable to misuse and abuse by humans" (Kenchington, 1990: 119). Coral reefs are delicate and recreational divers often damage them with unintentional or intentional physical contacts (Talge, 1993). Intensive use of diving sites, poor diving and business operation practices negatively affect the marine environment depleting its aesthetic quality (Liddle \& Kay, 1989; Phillips, 1992; Dixon et al., 1993; Davis \& Tisdell, 1995). Researchers have argued that better environmental knowledge and attitudes about coral reef ecosystems are essential in reducing the impacts and promoting environmentally responsible behaviours (Thapa, Graefe \& Meyer, 2006).

Nevertheless, the marine environment remains the focus of divers' attention (Dinmock \& Musa, 2015) and tourists are likely to appraise destinations from a sustainability perspective in evaluating the holistic tourism experience (IniestaBonillo et al, 2016). Although studies have been conducted on sustainability and customer satisfaction (See Luo \& Bhattacharya, 2006; Cotrell \& Vaske, 2006; IniestaBonillo et al., 2016), research specifically on sustainability and the tourist experience is scant. Taking into consideration these perspectives, it is important to comprehend if and how sustainability helps to shape the tourist experience. The aim of this study is to provide insights into sustainability issues affecting scuba diving as a memorable tourist experience and is of particular importance due to the nature of this form of tourism which occurs in fragile and unique settings.

Despite a significant number of studies conducted on scuba diving, limited studies exist on scuba diving as a memorable tourism experience. In recent years, the concept of tourist experience has become a focal aspect for tourism research and management (Tung \& Ritchie, 2011) because tourists seek a unique and customised experience when participating in a tourism activity (Hosany \& Witham, 2009; Pearce \& Zare, 2017). Moreover, it has been argued that memorable tourist experiences predict behavioural intentions better than customer satisfaction (Keiningham \& Vavra, 2001; Kim et al., 2012). Various studies have examined the importance of creating meaningful experiences and these studies support a number of underlying factors which characterise the tourist experience such as hedonism, refreshment, local culture, meaningfulness, knowledge, involvement, and novelty (Oh, Fiore, \& Jeong, 2007; Hosany \& Gilbert, 2010; Kim et al., 2012; Rageh et al., 2013). Understanding memorable experiences are important in destination management so as to increase 
the likelihood of delivering experiences to tourists which are "special, cherished and truly memorable" (Tung \& Ritchie, 2011: 1369).

It is being increasingly acknowledged that online reviews provide valuable data for assessing tourists' experiences (See Pearce \& Wu, 2016). During the past few years, the internet has become the key forum for customers to narrate their personal and memorable events via online communities (Cenni \& Goethals, 2017) and they have a predisposition to share with others those personal events that comprise a high expressive content (Lorenzetti \& Lugli, 2012). The growth and importance of online platforms on tourism thus leads to an enormous amount of consumergenerated online reviews (Ye et al., 2009). This study aims to investigate how the concept of scuba diving experience is presented through tourists' online reviews with a specific focus on gaining insight into consumers' perceptions of sustainability in the scuba diving experience. The next section reviews the methodology used for the research.

\section{Methodology}

Data was collected from Tripadvisor, the largest online network of travel consumers (O'Connor, 2010) and this method enabled the gathering of a large amount of data in a relatively short time-frame. All available customer reviews on Tripadvisor across all 57 diving operators in Mauritius were collected in the months of January and February 2017. These 3109 text reviews comprise over 283,500 words and cover the time span from 18 January 2014 to 3 February 2017. Five categories of travel groups including couples, families, friends, solo and business travelers were analysed. Special attention was paid to the content pertinent to sustainability factors in the scuba diving experience. In particular, all text relevant to sustainability were identified through careful reading and were coded. Consequently, a concept-theme map depicting tourists' understanding of perceptions the sustainability-related issues of scuba diving in Mauritius was generated.

\section{Results and Discussion}

Attention was paid to the content related to sustainability issues in the travel reviews. However, only a small proportion of reviews (89 extracts, $2.9 \%$ out of the total) mentioned environmental topics. The sustainability perceptions of tourists are not evenly distributed across different categories of travel groups. It can be seen from the Table 1 that solitary tourists are most concerned with the environment while business travellers did not mention sustainability. 
Table 1: Distribution of sustainability concerned diving tourists across groups

\begin{tabular}{|l|l|l|l|}
\hline Group & $\begin{array}{c}\text { Total number of } \\
\text { reviews }\end{array}$ & $\begin{array}{c}\text { Number of } \\
\text { sustainability } \\
\text { relevant reviews }\end{array}$ & $\begin{array}{c}\text { Proportion of } \\
\text { sustainability relevant } \\
\text { reviews }\end{array}$ \\
\hline Couple & 1378 & 44 & $3.19 \%$ \\
\hline Family & 707 & 17 & $2.40 \%$ \\
\hline Friend & 536 & 12 & $2.24 \%$ \\
\hline Solo & 454 & 16 & $3.52 \%$ \\
\hline Business & 34 & 0 & $0 \%$ \\
\hline Total & 3109 & 89 & $2.9 \%$ \\
\hline
\end{tabular}

The popular terms that tourists use to discuss sustainability and their frequencies can be seen in Table 2. It can be concluded that the condition of the environment and marine life, especially the coral reefs and fish, are the major sustainability concerns of the diving experience from the perspective of tourists. Sustainability conscious divers paid much attention to pollution, practices damaging environment (fishing and poaching), and diving operators' attitudes to nature.

Table 2: Sustainability relevant terms in travel reviews

\begin{tabular}{|l|l|l|l|l|l|}
\hline \multicolumn{1}{|c|}{ Term } & Frequency & \multicolumn{1}{c|}{ Term } & Frequency & \multicolumn{1}{c|}{ Term } & Frequency \\
\hline Environment & $16 / 50^{*}$ & Animal & $3 / 26$ & Litter & $2 / 2$ \\
\hline Nature & $12 / 27$ & Fishing & $6 / 34$ & Pollution & $2 / 4$ \\
\hline Protect & $2 / 22$ & Wildlife & $11 / 30$ & Damage & $10 / 19$ \\
\hline Conserve/-ation & $3 / 3$ & Coral & $4 / 286$ & Bags & $1 / 7$ \\
\hline Reserve & $6 / 28$ & Reef & $32 / 264$ & Poach & 1 \\
\hline Respect/esteem & $18 / 56$ & Marine & $18 / 132$ & & \\
\hline
\end{tabular}

${ }^{*}$ The frequency of a term used to discuss sustainability out of the total frequency of a term.

Then the reviews mentioning sustainability issues were separated from the overall sample and a Leximancer process was run. Seven prominent themes jointly formed a whole picture displaying the view among sustainability-reviews of tourists, in terms of diving experience in Mauritius (see Figure 3). Firstly, the "reef" emerged as an important theme which confirms tourists' concern for marine life. Importantly, concepts of "respect" and "environment" were essential concepts contributing to the theme "team" and the concept "team" is closed related to the concept "nature". Therefore, it can be concluded that tourists value operators' attitudes to nature and the environment. For instance, divers wrote "the diving centre is not only offering 
dive experiences for all level of divers, they are also teaching, helping preserve marine life, and led beach and underwater clean-up days". Diving instructors' respect of nature and their responsible behaviours to protect the environment are essential to produce a positive experience for divers who are conscious of sustainability.

Thirdly, the concept "PADI" (Professional Association of Diving Instructors) appeared and was positioned into the theme "dive". Special focus on "PADI" confirms that it is the most popular form of international diving certification provided in Mauritius and its divers and courses are synonymous of a higher level of professionalism, safety and environmental stewardship as reflected in the following sentence "nice crew who follow PADI best practices and treat marine life and environment with respect". Contrastingly, in rare instances when the underwater environment was not respected, experienced divers did not hesitate to voice out intolerance to such behaviours: "this is unacceptable. Divers should not touch the wildlife. ESPECIALLY a fully qualified PADI professional such as himself. We are there as spectators and to spectate only. I also saw divers, on a dive by X Co Ltd, touching, standing on, finning all over the reef. I cannot stand this." Staff respect towards the coral reef is essential in minimising diving impacts and the sustainable practices of the dive operators shape the tourism experience for customers.

More details of diving experience in Mauritius can be found in the themes "boat" and "dive" which depict tourists' diving trip in Mauritius. Firstly, the "beautiful" marine sceneries make such diving trips impressive including "sea", "fish" and "large" marine species. The concepts of "site" indicate tourists' commute between the hotel and diving sites. Many reviewers stressed the easy and fast accessibility of diving sites "most dive sites are 10-20 minutes away by boat" and "the sites within a short boat ride are spectacular". 


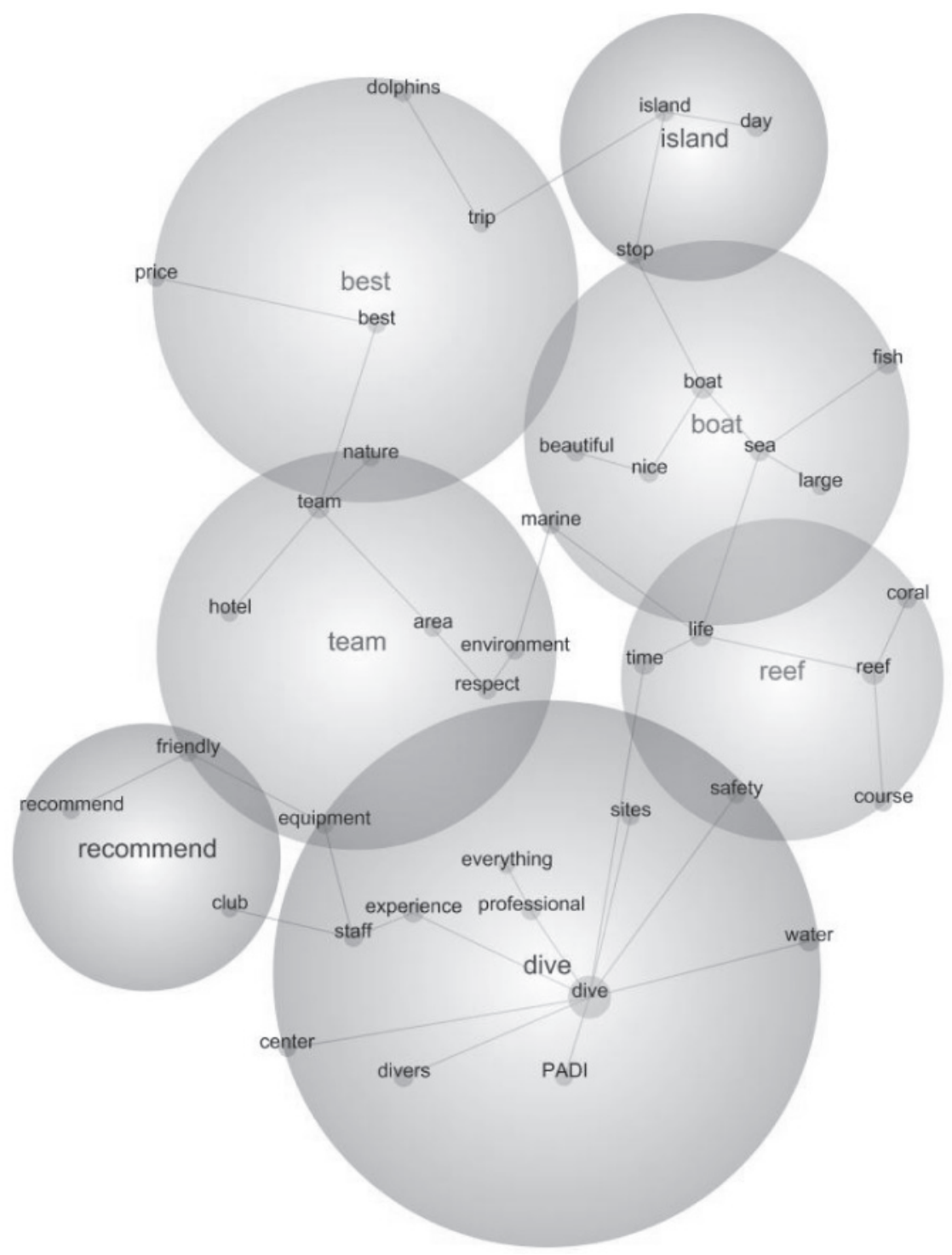

Figure 3 Conceptual map of sustainability relevant diving experience in Mauritius

Another essential theme is "best" which expresses tourists' overall affective evaluation of their diving experience. Particularly, reviewers highly appreciated the boat "trip" and the service delivery of the "team" of dive operators. Moreover, the former also perceived that the natural environment was attractive and viewing "dolphins" contributed to the best experience. "Recommend" also emerged as a fundamental theme indicating tourists' positive behavioural intentions. 


\section{Conclusion}

Research specifically investigating sustainability and the tourist experience is limited although there is has been an increasing amount of studies on scuba diving satisfaction and experience (See Musa, 2002; Dinmock \& Musa, 2015). This study contributes to enhance knowledge on scuba diving experience using online testimonials as opposed to most studies on the topic which have made use of more traditional methods such as questionnaires and interviews. The Leximancer, a content analysis tool, was used and allowed the comparison of the contents of tourists' online narration of sustainability in the scuba diving activity based on reviews provided by the tourists after their experience. The tags used serve to label the Leximancer map and do not represent the researchers influencing theme formation. The findings of the study were based on the online reviews of international tourists who have expressed and shared in their own voices regarding their scuba diving experiences.

The study attempted to link tourists' evaluations of their scuba diving experiences with the theme sustainability. The most significant key themes which emerged were: dive, best, team, boat, reef, island and recommend. The term "reef" and "island" show that the marine environment and the local setting (island) are important factors in determining the scuba experience. A well preserved marine ecosystem with respect for environmental practices are essential for this segment of divers. Moreover, divers particularly value the context of an island as it has unique flora and fauna to explore. The consumers who expressed sustainability concerns through online reviews were in general more experienced and paid more attention to the professionalism of divers in promoting environmental stewardship and safety practices expressed in their high educational expectations associated with the PADI certification. Moreover, "solo" tourists were most concerned about sustainability as opposed to those in groups or families who are more concerned with enjoying the experiencing with loved ones. Besides, "solo" tourists had in general more experience in scuba diving and had conducted a higher number of dives. Experienced divers have advanced knowledge and information about marine life and share concerns for healthy coral reefs and developing appropriate attitudes toward nature. These findings are consistent with past studies regarding the concerns of environmental impacts with respect to scuba diving (Hillmer-Pregam, 2014; Dinmock \& Musa, 2015). Past studies have also shown that dive instructors have an impact on sharing knowledge with tourists regarding low impact diving practices (Barker \& Roberts, 2004) and therefore the PADI certification represents a set of training standards that need to be maintained through accurate communication with tourists and interaction with the underwater world.

It is important for destination managers and dive operators to understand the importance of sustainability in the diving experience. Moreover, recognising tourists' 
concern about sustainability can encourage dive operators to further understand and focus on enhancing their contributions to conservation issues and better managing impacts. In order to sustain the scuba diving industry and offer quality scuba diving experiences, destinations have to adopt sustainable principles and practices as highlighted by Dinmock \& Musa (2015). The key stakeholders in scuba diving need to properly manage this activity, including dive operators since their attitudes and behaviour largely determine the extent of the impacts on the coral reef ecosystems. Since they are also the main users and direct beneficiaries of immediate socio-economic benefits, dive operators need to acknowledge their responsibility in protecting and conserving the marine environment. Moreover, at the moment overcrowding is not a concern as there are various dive sites scattered in different locations around of the island. However, as tourism numbers grow in fragile ecosystems, large influx of tourists to a relatively small island can have serious negative impacts and put the environment under enormous pressure. Reducing the negative environmental impacts can help to conserve the socio-economic sustainability of scuba diving and enhance the dive experience.

Some limitations of the current study need to be acknowledged. In this study the online reviews used and assessed were only in English while those who commented in other languages were excluded because they were low in numbers and/or the authors' inability to understand the comments (e.g., German, Italian). Further work thus can be considered to understand the themes from these international tourists.

\section{References}

Barker, N. H., \& Roberts, C. M. (2004). Scuba diver behaviour and the management of diving impacts on coral reefs. Biological Conservation, 120(4), 481-489.

Cenni, I., \& Goethals, P. (2017). Negative hotel reviews on TripAdvisor: A crosslinguistic analysis. Discourse, Context \& Media, 16, 22-30.

Cottrell, S. P., \& Vaske, J. J. (2006). A framework for monitoring and modeling sustainable tourism. Electronic Review of Tourism Research, 4(4), 74-84.

Davis, D. and Tisdell, C. (1995). Recreational scuba diving and carrying capacity in marine protected areas. Ocean and Coastal Management, 26, 19-40.

Dimmock, K. \& Musa, G. (2015). Scuba diving tourism system: a framework for collaborative management and sustainability. Marine Policy, 54, 52-58.

Dixon, J. A., Scura, L. F. \& van't Hof, T. (1993). Meeting ecological and economic goals: marine parks in the Caribbean. Ambio 22, 117-125.

Giglio, V. J., Luiz, O. J., \& Schiavetti, A. (2015). Marine life preferences and perceptions among recreational divers in Brazilian coral reefs. Tourism Management, 51, 4957. 
Hawkins, J. P., \& Roberts, C. M. (1992). Effects of recreational SCUBA diving on forereef slope communities of coral reefs. Biological Conservation, 62(3), 171-178.

Hawkins, J.P., Roberts, C.M., Van'T Hof, T., De Meyer, K., Tratalos, J. \& Aldam, C., 1999. Effects of recreational scuba diving on Caribbean coral and fish communities. Conservation Biology, 13(4), 888-897.

Hillmer-Pegram, K.C. (2014). Understanding the resilience of dive tourism to complex change. Tourism Geographies, 16(4), 598-614.

Hosany, S., \& Gilbert, D. (2010). Measuring tourists' emotional experiences toward hedonic holiday destinations. Journal of travel research, 49(4), 513-526.

Hosany, S. \& Witham, M. (2009) Dimensions of cruisers' experiences, satisfaction and intention to recommend, Working Paper (SoMWP0905)

Iniesta-Bonillo, M. A., Sánchez-Fernández, R., \& Jiménez-Castillo, D. (2016). Sustainability, value, and satisfaction: Model testing and cross-validation in tourist destinations. Journal of Business Research, 69(11), 5002-5007.

Liddle, M. \& Kay, A. M. (1989). Impact of human trampling in different zones of a coral reef flat. Environmental Management, 4, 509-520.

Lorenzetti, R., \& Lugli, L. (2012). Sharing autobiographical memories: Effects of arousal and memory. Studies in Communication Sciences, 12(1), 53-57.

Luo, X., \& Bhattacharya, C. B. (2006). Corporate social responsibility, customer satisfaction, and market value. Journal of marketing, 70(4), 1-18.

Kenchington, R. A. (1990). Managing Marine Environments. New York: Taylor and Francis.

Keiningham, T. L., \& Vavra, T. G. (2001). The customer delight principle: Exceeding customers' expectations for bottom-line success. McGraw-Hill.

Kim, J. H., Ritchie, J. B., \& McCormick, B. (2012). Development of a scale to measure memorable tourism experiences. Journal of Travel Research, 51(1), 12-25.

Kirkbride-Smith AE, Wheeler PM \& Johnson ML (2013) The Relationship between Diver Experience Levels and Perceptions of Attractiveness of Artificial Reefs - Examination of a Potential Management Tool. PLoS ONE 8(7): e68899. doi:10.1371/journal.pone.0068899.

Merchant, S. (2011) Negotiating Underwater Space: The Sensorium, the Body and the Practice of Scuba Diving, 11 (3), 215-234.

Musa, G. (2002). Sipadan: A scuba-diving paradise: An analysis of tourism impact, diver satisfaction and tourism management. Tourism Geographies: An international Journal of Tourism Space, Place and Environment, 4(2), 195-209. 
O'Connor, P. (2010) Managing a hotel's image on TripAdvisor, Journal of Hospitality Marketing and Management, 19: 754-772.

Oh, H., Fiore, A. M., \& Jeoung, M. (2007). Measuring experience economy concepts: Tourism applications. Journal of travel research, 46(2), 119-132.

Pearce, P. L., \& Wu, M. Y. (2016). Tourists' Evaluation of a Romantic Themed Attraction Expressive and Instrumental Issues. Journal of Travel Research, 55(2), 220-232.

Pearce, P. L., \& Zare, S. (2017). The orchestra model as the basis for teaching tourism experience design. Journal of Hospitality and Tourism Management, http://dx.doi. org/10.1016/j.jhtm.2017.01.004

Phillips, S. (1992). The Dive Tourism Industry of Byron Bay: A Management Strategy for the Future. Integrated Project. Lismore, Australia: Centre for Coastal Management, Southern Cross University.

ProfessionalAssociationofDivingInstructors(PADI).(2005).Diverstatistics. Retrieved July 16, 2005, from http://www.padi.com/english/common/padi/statistics/2.asp.

Rageh, A., Melewar, T. C., \& Woodside, A. (2013). Using netnography research method to reveal the underlying dimensions of the customer/tourist experience. Qualitative Market Research: An International Journal, 16 (2), 126-149.

Talge, H. (1993). Impact of recreational divers on scleractinian corals at Looe Key, Florida. In Proceedings of the 7th International Coral Reef Symposium (Vol. 2, pp. 1077-1082). Mangalio: University of Guam Press.

Tapsuwan S. \& Asafu-Adjaye J. (2008) Estimating the economic benefit of SCUBA diving in the Similan Islands, Thailand. Coastal Management, 36, 431-42.

Thapa, B., Graefe, A. R., \& Meyer, L. A. (2006). Specialization and marine based environmental behaviors among SCUBA divers. Journal of Leisure Research, 38(4), 601.

Tung, V. W. S., \& Ritchie, J. B. (2011). Exploring the essence of memorable tourism experiences. Annals of tourism research, 38(4), 1367-1386.

Ye, Q., Law, R., \& Gu, B. (2009). The impact of online user reviews on hotel room sales. International Journal of Hospitality Management, 28(1), 180-182. 